\title{
Protective Effect of 6-Gingerol Against Cardiotoxicity Induced by Doxorubicin
}

\author{
Mahmoud A. Mansour", Saleh A. Bakheet, Abdulaziz M. Aleisa, Salim S. Al-Rejaie, \\ Abdulaziz A. AL-Yahya, Mubarak El-Ameen and Othman A. Al-Shabanah
}

\begin{abstract}
Pharmacology Department, Faculty of Pharmacy, King Saud University, P.O. Box 2457, Riyadh 11451, Kingdom of Saudi Arabia
\end{abstract}

\begin{abstract}
Doxorubicin (DOX) has a wide spectrum of antitumor activity with dose-related cardiotoxicity as a major side effect. This cardiotoxicity has been suggested to result from enhanced oxidative stress caused by oxygen centered free radicals. The present study was performed to investigate the influence of the antioxidant 6-gingerol on cardiotoxicity induced by doxorubicin (DOX). A single dose of DOX $(20 \mathrm{mg} / \mathrm{kg}$ i.p.) induced myocardial toxicity after 48 hrs, manifested biochemically by a significant elevation in the following serum enzymes activities: creatine phosphokinase (E.C.2.7.3.2), lactate dehydrogenase (E.C.1.1.1.27), aspartate transaminase (E.C.2.6.1.1) and serum cardiac isoenzyme creatine phosphokinase (MB). Administration of 6-gingerol (10 mg/kg/day p.o.) in drinking water starting 5 days before and continuing during the experimental period significantly ameliorated myocardial toxicity induced by DOX. The amelioration of cardiotoxicity was evidenced by significant reductions in serum enzymes activities and cardiac isoenzyme. The current data support 6-gingerol as a potentially selective cardioprotective agent, against cardiotoxicity induced by DOX and it may therefore improve the therapeutic index of DOX.
\end{abstract}

Keywords: Doxorubicin, 6-gingerol, cardiotoxicity, aspartate transaminase, creatine phosphokinase, lactate dehydrogenase, mice.

\section{INTRODUCTION}

Doxorubicin (DOX) represents a class of antineoplastic drugs. It is an anthracyclin antibiotic. It is effective against several human tumors including e.g. breast cancer, lung cancer and acute leukemias [1] and in animal tumor models [2]. Like most of the anti-neoplastic drugs, DOX produces a number of side effects, mainly cardiotoxicity and myelosuppression, which limit its clinical use [3-5].

It has been suggested by many investigators that, the cellular damage induced by DOX is mediated by the formation of an iron-DOX complex that generate free radicals $[6,7]$ which in turn cause severe damage to plasma membrane and interfere with the cytoskeleton assembly [8]. Tissues with less developed antioxidant defense mechanism such as the heart are highly susceptible to injury by oxygen free radicals induced by DOX [9]. Consequently, there is a much great interest to increase the clinical usefulness of DOX by developing new agents in order to counteract the functional disorders induced by DOX to make its user safe [10]. Therefore, considerable efforts have been made on using antioxidants and iron-chelators to protect the heart against DOX toxicity. Initial attempts to use traditional antioxidants, like $\mathrm{N}$ acetylcystiene [11], $\alpha$-tocopherol [12] in the prevention of DOX -induced cardiotoxicity were not very successful. Dexrazoxane, the only drug presently approved by FDA to prevent DOX induced cardiotoxicity, is an iron chelator and possesses potent antioxidant properties. But, due to the high

*Address correspondence to this author at the Department of Pharmacology, College of Pharmacy, King Saud University, P.O. Box 2457, Riyadh 11451, Saudi Arabia; Tel: 9661-4677212; Fax: 9661-4677200;

E-mail: mansour1960us@yahoo.com incidence of dexrazoxane-induced myelosuppression, its use has also been limited to some advanced stages of malignant disorders [13]. Therapeutic strategies, designed to augment cellular endogenous defense systems have been identified as a promising approach to combat oxidative stress-associated disease conditions [14].

Plant of ginger (Zingiber officinale) family is one of the most highly consumed dietary substances in the world. The oleoresin from rhizhome of ginger contains pungent ingredients including the phenolic compounds, gingerol, shoagol, and zingerone [15]. 6-gingerol (1-(4'-hydroxy-3'-methoxyphenyl)-5-hydroxy-3-decanone), the major pungent principle of ginger, possesses many interesting pharmacological and physiological activities: antioxidant, anti-inflammatory and anti-tumor promoting activities [15]. Ahmed et al. [16] has shown that addition of ginger extract (1\%) to normal diet of rats prevent formation of free radicals and maintain integrity of erythrocytes. In addition Bhandari et al. [17] reported that ethanolic extract of Zingiber officinalis can protect tissues from lipid peroxidation.

Anticancer and chemopreventive activities of 6-gingerol have been reported. 6-gingerol exerted inhibitory effects on cell viability and DNA synthesises, also induced apoptosis in pro-myelocytic leukemia HL-60 cells [18] and has affects of chemoprevention to gastric-intestinal cancers [19].

Based on these results, the present work describes further experiments, which were carried out to reach deeper insight into possible synergistic antineoplastic effect together with attenuation the cardiotoxicity induced by DOX. Measurement of serial changes in serum enzymes, creatine phosphokinase (CPK), lactate dehydrogenase (LDH) and aspartate transaminase (AST) as well as cardiac isoenzyme CPK (MB) and LDH assessed the cardiotoxicity. 


\section{MATERIALS AND METHODOLOGY}

\section{Chemicals}

6-gingerol was purchased from CromaDex (Muirlands, CA. USA), while DOX was provided as a gift sample from Farmitalia, Carlo Erba, Milan, Italy. All remaining chemicals were of the highest grade commercially available.

\section{Animals}

Male swiss albino mice, weighing 20-25 g were used. They were obtained from the Experimental Animal Care Center of King Saud University, Riyadh, KSA. Animals were maintained under standard conditions of temperature $24 \pm 1^{\circ} \mathrm{C}$ and $55 \pm 5 \%$ relative humidity with regular $12 \mathrm{~h}$ light: $12 \mathrm{~h}$ dark cycle and allowed free access to standared laboratory food (Purina Chow) and water.

\section{Animal Treatments}

The animals were divided at random into six groups of 10 animals each. The first group (control) received vehicles used for DOX (physiological saline solution, i.p.). The second group, received 6-gingerol in drinking water $(10 \mathrm{mg} / \mathrm{kg} /$ day p.o.), the calculated dose of 6-gingerol based on the average daily intake of water. The third and fourth groups were injected with DOX $(20 \mathrm{mg} / \mathrm{kg}$ i.p.). The last two groups (5 and 6) received 6-gingerol in drinking water for 5 consecutive days before and continuing during the experimental period of DOX injection ( $20 \mathrm{mg} / \mathrm{kg}$ i.p.) for 24 and $48 \mathrm{hrs}$. The selected concentration of 6-gingerol and the schedule of dose administration were chosen as guided by our own preliminary experiments. At 24 and 48 hrs later after DOX injection, the mice were anaesthetized under light ether anaesthesia and the blood samples were withdrawn from the retroorbital venous plexus, into non-heparinized tubes. Serum was separated by centrifugation for $5 \mathrm{~min}$ at $1000 \mathrm{xg}$ and stored at $-20^{\circ} \mathrm{C}$ until analysis.

\section{Biochemical Parameters}

AST enzyme activity was measured in serum colometrically according to method described by [20], while CPK and LDH were determined kinetically by [21, 22] respectively, using diagnostic kits (bioMērieux-RCS Lyon-France). CPKMB cardiac isoenzyme activity was measured according to method of [23].

\section{Statistical Analysis}

Data are expressed as means \pm SEM. Statistical comparison between different groups were done using one way analysis of variance (ANOVA) followed by Tukey-Kramer multiple comparison test, to judge the difference between various groups. Significance was accepted at $\mathrm{P}<0.05$.

\section{RESULTS}

\section{Effect of 6-Gingerol on DOX-Induced Changes in Serum Enzymes Activities After 24 Hrs}

Intraperitoneal administration of DOX (20 mg/kg i.p.) for $24 \mathrm{hrs}$ caused a significant elevation of serum enzyme LDH activity and non significant elevation of the following enzymes AST and CPK activities (Table $\mathbf{1}$ ).

Pretreatment of the animals with 6 -gingerol $(10 \mathrm{mg} / \mathrm{kg}$ p.o.) 5 days before and continued $24 \mathrm{hrs}$ in DOX treatment resulted in normalization or even profound reduction in the serum level of AST and CPK. Likewise, 6-gingerol induced a remarkable decrease in the level of serum LDH enzyme activity (Table 1).

\section{Effect of 6-Gingerol on DOX-Induced Changes in Serum Enzymes Activities After 48 Hrs}

Intraperitoneal administration of DOX (20 mg/kg i.p.) for $48 \mathrm{hrs}$ induced a double increment in serum enzymes activities LDH, CPK and threefold increment in AST activity after 48 hrs (Table 2).

Pretreatment of the animals with 6-gingerol $(10 \mathrm{mg} / \mathrm{kg}$ p.o.) 5 days before and continued $48 \mathrm{hrs}$ in DOX treatment provoked a pronounced inhibition of the enzymes activities as evidenced by normalization of the AST and CPK activities. Although, LDH activity has been reduced but the protective effect of 6-gingerol did not reach significant level (Table 2).

\section{Effect of 6-Gingerol on DOX-Induced Changes in Serum Cardiac Isoenzyme CK-MB After 24 and 48 Hrs}

Intraperitoneal administration of DOX (20 mg/kg i.p.) for $48 \mathrm{hrs}$ caused a fivefold increase in the serum cardiac isoenzyme CPK-MB (Table 3).

Pretreatment of the animals with 6-gingerol (10 $\mathrm{mg} / \mathrm{kg} /$ day p.o.) 5 days before and continued 24 and $48 \mathrm{hrs}$ in DOX treatment, the activity of the enzyme has been markedly impeded as evidenced by normalization of the enzyme activity after $24 \mathrm{hrs}$ and $58 \%$ reduction in the cardiac isoenzyme CPK-MB activity after $48 \mathrm{hrs}$ (Table $\mathbf{3}$ ).

\section{DISCUSSION}

As predicted, administration of DOX (20mg/kg i.p.) resulted in an overt cardiotoxicity as evidenced in the serum by

Table 1. Effect of 6-Gingerol on DOX-Induced Changes in Mice Serum Enzyme Activities After 24 Hours

\begin{tabular}{|c|c|c|c|c|}
\hline Parameters & Control & 6-Gingerol & DOX & DOX+ 6-Gingerol \\
\hline \hline CPK (U/L) & $204.5 \pm 28.4$ & $160.8 \pm 16.5$ & $308 \pm 40.2$ & $121.7 \pm 11.5^{\#}$ \\
\hline LDH (U/L) & $579.1 \pm 77.9$ & $663.8 \pm 109.8$ & $997.2 \pm 54.2^{*}$ & $921 \pm 105.6$ \\
\hline AST (U/L) & $83.6 \pm 7$ & $77.9 \pm 15.7$ & $164.1 \pm 18.9$ & $74.7 \pm 26.3$ \\
\hline
\end{tabular}

All data represent mean values $\pm \mathrm{SE}(\mathrm{n}=10)$

6-gingerol was given in drinking water for 5 consecutive days $(10 \mathrm{mg} / \mathrm{kg} /$ day p.o.) before and continuing during DOX treatment. Blood samples were obtained $24 \mathrm{hrs}$ after DOX (20 $\mathrm{mg} / \mathrm{kg}$ i.p).

*Significant difference from control group.

${ }_{*}^{\#}$ Significant difference from DOX group.

${ }^{*} \mathrm{P}<0.05$. 
Table 2. Effect of 6-Gingerol on DOX-Induced Changes in Mice Serum Enzyme Activities After 48 Hours

\begin{tabular}{|c|c|c|c|c|}
\hline Parameters & Control & 6-Gingerol & DOX & DOX+ 6-Gingerol \\
\hline \hline CPK (U/L) & $204.5 \pm 28.4$ & $160.8 \pm 16.5$ & $469.6 \pm 56.8^{*}$ & $275.2 \pm 19.6^{\#}$ \\
\hline LDH (U/L) & $579.1 \pm 77.9$ & $663.8 \pm 109.8$ & $1217 \pm 82.9^{*}$ & $984 \pm 45.4^{*}$ \\
\hline AST (U/L) & $83.6 \pm 7$ & $77.9 \pm 15.7$ & $239.1 \pm 49^{*}$ & $55 \pm 2.2^{\#}$ \\
\hline
\end{tabular}

All data represent mean values $\pm \mathrm{SE}(\mathrm{n}=10)$.

6-gingerol was given in drinking water for 5 consecutive days $(10 \mathrm{mg} / \mathrm{kg} /$ day p.o.) before and continuing during DOX treatment. Blood samples were obtained $48 \mathrm{hrs}$ after DOX (20 $\mathrm{mg} / \mathrm{kg}$ i.p).

*Significant difference from control group.

"Significant difference from DOX group.

$*^{\#} \mathrm{P}<0.05$.

the marked elevations of creatine phosphokinase, lactate dehydrogenase and aspartate transaminase enzymes activities. Cardiotoxicity was also confirmed by significant increase of cardiac isoenzyme creatine-phosphokinase (MB) at 48 hrs after DOX treatment. The time point selected in our study was based upon preliminary data from our lab showing the onset of the maximum heart injury induced by DOX. Thus, the observed cardiotoxic effects of DOX in mice were similar to those previously reported [24, 25].

The cardiotoxic potential of DOX, limits its clinical use [14]. The beneficial effects of 6-gingerol in the prevention several tissues damage, including heart and kidney have been reported [26, 27]. Treatment of mice with 6-gingerol alone $(10 \mathrm{mg} / \mathrm{kg} /$ day p.o.) for 5 days did not induce any changes in the measured biochemical parameters. However, administration of 6-gingerol in drinking water $(10 \mathrm{mg} / \mathrm{kg}$ p.o.) for 5 consecutive days before and continued during experimental period in DOX treatment $(20 \mathrm{mg} / \mathrm{kg}$ i.p.) renders mice less susceptible to heart damage induced by treatment with DOX. This protection was evidenced in the serum as the marked elevations of creatine phosphokinase, lactate dehydrogenase and aspartate transaminase activities were significantly decreased.

The rationale of 6-gingerol schedule of dose administration was to maintain of a steady sufficient plasma concentration of 6-gingerol before, during and after the critical period of DOX-induced toxicity, since the biochemical changes that occur in the heart after DOX administration are of crucial importance in determining the extent of a cardio-toxic lesion [24]. Since DOX is converted into its semiquinone form in the cardiac myocyte by myocardial CYP450 and flavin monoxygenases. The semiquinone form is a toxic, short-lived metabolite and interacts with molecular oxygen and initiates a cascade of reaction, producing reactive oxygen species
(ROS) [28]. Another reported mechanism of DOX-induced oxidative stress is the formation of an anthracycline-iron $\left(\mathrm{Fe}^{2+}\right)$ free radical complex [29]. The latter reacts with hydrogen peroxide to produce hydroxyl $(\mathrm{OH} \bullet)$ radical. ROS react with lipids, protein and other cellular constituents to cause damage to mitochondria and cell membranes of the heart muscle cells. Due to the presence of a less developed antioxidant defense mechanism, heart is particularly vulnerable to injury by anthracycline-induced reactive oxygen species [11]. 6-Gingerol, has been shown as a membrane lipid antioxidant and showed extremely high superoxide anion radical scavenging ability in pure chemical system [30]. On the basis of these findings, 6-gingerol might play an important role as an endogenous antioxidant and could be applicable as a cytoprotective agent against damage mediated by chemotherapeutic agents.

The protective effect of 6-gingerol on DOX-induced cardiac damage is in fully agreement with a previous study of Kuhad et al. [26] who demonstrated a protective effect of 6gingerol against cisplatin-induced renal dysfunction in rats. These beneficial effects of 6-gingerol are consistent with alleviation of DOX-mediated cardiotoxicity by other well known antioxidants such as $\mathrm{N}$-acetylcysteine [31] and ascorbic acid [32]. However, other mechanisms than lipid peroxidation may contribute to determine the overall toxicity of DOX in vivo [33-35], the present findings may indirectly support the association of free radical species in the cardiotoxic mechanism and the protective effect induced by 6 gingerol may be related to its reported antioxidant effect.

Our results may indicate that 6-gingerol is beneficial as a protective agent against cardiotoxicity induced by DOX in mice. Further studies are highly needed to elucidate the mechanism(s) of protection and the effect of 6-gingerol on the anti-tumor activity of DOX.

Table 3. Effect of 6-Gingerol on DOX-Induced Changes in Mice Serum Cardiac Isoenzyme CPK-MB Activity After 24 and 48 Hours

\begin{tabular}{|c|c|c|c|c|}
\hline Parameters & Control & 6-Gingerol & DOX & DOX+ 6-Gingerol \\
\hline \hline CK-MB $(24 \mathrm{hrs})$ & $48.7 \pm 9.1$ & $39.2 \pm 11.4$ & $151.8 \pm 39.8$ & $42.2 \pm 2.7$ \\
\hline CK-MB $(48 \mathrm{hrs})$ & $48.7 \pm 9.1$ & $39.2 \pm 11.4$ & $260.2 \pm 44.6^{*}$ & $111 \pm 37.7^{\sharp}$ \\
\hline
\end{tabular}

All data represent mean values $\pm \mathrm{SE}(\mathrm{n}=10)$

6-gingerol was given in drinking water for 5 consecutive days (10 mg/kg p.o.) before and continuing during DOX treatment. Blood samples were obtained 24 and 48 hrs after DOX $(20 \mathrm{mg} / \mathrm{kg}$ i.p).

*Significant difference from control group.

\#Significant difference from DOX group.

${ }^{\#} \mathrm{P}<0.05$. 


\section{ACKNOWLEDGEMENTS}

This study was supported by the Research Center, College of Pharmacy, King Saud University, Grant No. C.P.R.C.208

\section{REFERENCES}

[1] Blum, R.H.; Carter, S.K. Ann. Intern. Med., 1974, 80, 249.

[2] Rosenberg, B. Adv. Exp. Med. Biol., 1977, 91,129.

[3] Al-Harbi, M.; Al-Garably, N.; Al-Shabanah, O.; Al-Bekairi, A.; Osman, A.; Tawfik, H. Cancer Chem. Pharmacol., 1992, 31, 200.

[4] Kojima, S.; Icho, T.; hayashi, M.; Kajiwara, Y.; Kitabatake, K.; Kubota, K. J. Pharmacol. Exp. Ther., 1993, 266, 1699.

[5] Osman, A.; Al-Shabanah, O.; Al-Harbi, M.; Al-Garably, N.; AlBekairi, A.; Tawfik, H.; Aziz, S. Med. Sci. Res., 1993, 21, 193.

[6] Olsen, H.M.; Capen, C. Toxicol. Appl. Pharmacol., 1978, 44, 605.

[7] Powis, G. Free Radical Biol. Med., 1989, 6, 63.

[8] Algria, A.; Rodriguez, M.; Hermandez, J. Biochem. Biophys. Acta, 1990, 1035, 51

[9] Olsen, R.D.; Mushlin, P.S. FASEB J., 1990, 4(13), 3076.

[10] Dorr, R.T. Semin. Oncol., 1996, 23(4) Suppl. 8, 23.

[11] Mayer, C.; Bonow, R.; Palmeri, S.; Jenkins, J.; Corden, B.; Locker, G. Semin. Oncol., 1983, 10(suppl-1), 53.

[12] Nagata, Y.; Takata, J.; Karube, Y.; Matsushima, Y. Biol. Pharm. Bull., 1999, 22(7), 698.

[13] Seifert, C.F.; Nesser, M.E.; Thompson, D.F. Ann. Pharmacother., 1994, 28(9), 1063

[14] Steare, S.E.; Yellon, D.M. J. Mol. Cell Cardiol., 1995, 276, 65.

[15] Surh, Y.J.; Lee, E.; Lee, J.M. Mutat. Res., 1998, 402, 259.

[16] Ahmed, R.S.; Seth, V.; Banerjee, B. Indian J. Experim. Biol., 2000, 38, 604 .

[17] Bhandari, U.; Kanojia, R.; Pillai, K. J. Ethenopharmacol., 2005, 97, 227.

[18] Lee, E.; Surh, Y.J. Cancer Lett., 1998, 134, 163.
[19] Park, Y.; Wen, J.; Bang, S.; Park, S.W.; Song, S.Y. Yonsi Med. J., 2006, 47(5), 688

[20] Reitman, S.; Frankel, S. Am. J. Clin. Pathol., 1957, 28, 56.

[21] Swanson, J.; Wilkinson, J. Standard methods of clinical chemistry Vol. 7 Academic Press, New York, In: Cooper G. R (ed) 1972 PP 33.

[22] Bergmeyer, U.; Bernt, E.; Hess, E. Weinheim, Verlag Chemie Bergmeyer, U (ed) 1965, p736.

[23] Kaschmar, J.; Moss, D. Fundamental of clinical chemistry W.B Saunders, Philaselphia, London, Mexico city In teitz W (ed) 1982 pp 565.

[24] Al-Shabanah, O.A.; Badary, O.A.; Nagi, M.N.; Al-Gharably, N.M.; Al-Rikabi, A.C.; Al-Bekairi, A. J. Exp. Clin. Cancer Res., 1998a, 17(2), 193.

[25] Al-Shabanah, O.; Mansour, M.; El-Kashef, H.; El-Bekairi, A. Biochem. Mol. Biol. Int., 1998b, 45(2), 419.

[26] Kuhad, A.; Tirkey, N.; Pilkhwal, S.; Chopra, K. Biofactors, 2006 , 26(3), 189

[27] Lam, R.Y.; Woo, A.Y.; Leung, P.S.; Cheng, C.H. J. Am. Coll. Nutr., 2007, 26(3), 333.

[28] Davies, K.J.; Doroshow, J.H. J. Biol. Chem., 1986, 261, 3060

[29] Sugioka, K. Nakano, M. Biochim. Biophys. Acta, 1982, 713(2), 333.

[30] Aeschbach, R.; Loliger, J.; Scott, B.C.; Murcia, A.; Butler, J.; Halliwell, B.; Aruoma, O. Food Chem. Toxicol., 1994, 32(1), 31

[31] Doroshow, J.H.; Locker, G.Y.; Ifrim, I.; Myers, C.E. J. Clin. Invest., 1981, 68, 1053.

[32] Shimpo, K.; Nagatsu, T.; Yamada, K.; Sato, T.; Niimi, H.; shamoto, M.; Takeuchi, T.; umezawa, H.; Fujita, K. Am. J. Clin Nutr., 1991, 54, 1294S.

[33] Sridhar, R.; Dwivedi, C.; Anderson, J.; Baker, P.B.; Sharma, H.M.; Desai, P.; Engineer, F.N. J. Natl. Cancer Inst., 1992, 84, 1653.

[34] Ueki, S.; Miyoshi, M.; Shido, O.; Hasegawa, J.; Watanabe, T. Eur. J. Pharmacol., 2008, 5, 1654

[35] Lee, S.H.; Cekanova, M.; Baek, S.J. Mol. Carcinog., 2008, 47(3), 197. 